\title{
Soil Resistivity Adequacy Assessments: Case Study of Proposed School of Environmental Technology Building Federal University of Technology, Akure
}

\author{
M. O. Oyeleye and T. D. Makanju
}

\begin{abstract}
Earthing system are used to divert faulty currents to the ground or earth. Thus, a properly designed earthing system capable of dissipating fault currents safely to the ground or earth is required for safety of life and property hence the focus of this project in determining earthing resistance/resistivity adequacy of a Proposed School of Environmental Technology Building (PHASE III), Federal University of Technology, Akure, Nigeria. 4-point measuring technique, Wernner method, using digital earth tester, model 6472-AEMC is used in this work. The site is divided into five transverse for the tree buildings on site. The result shows that the earthing resistance of one building (transverses 1 and 3) generally varies from $3.9 \Omega$ to $54 \Omega$, second building: $2.3 \Omega$ to $11.9 \Omega$ and for third building: $2.2 \Omega$ to $6.4 \Omega$. Of the samples taken, building 1, 2 and 3 conformed to $4 \%, 47 \%$ and $50 \%$ of International Electrochemical Standard (IEC) and 48\%, 60\% and $100 \%$ of British International Standard (BIS). Transverse 5 is the best transverse for earthing because $50 \%$ of the points met IEC and $100 \%$ of the points met BIS standard for earthing resistance value. Earthing rod or mat can be installed at some points in building 1 and 2 in their transverse but not at every point but at any point in building 3 transverse. Earthing rod or mat at can be installed at $150 \mathrm{~mm}$ (minimum) in the transverse that meet up the international code's resistance value requirement. The result also establishes that resistance is directly proportional to soil resistivity, the lower the earth resistance the lower the soil resistivity. Building 3 which is

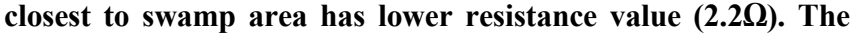
site is okay for earthing without any earthing improvement. Earthing resistance value test should be carried out on site prior earthing installation.
\end{abstract}

Index Terms-Wenner-Method, Soil-Resistivity, EarthValues, Earth-Resistance, Fault Current.

\section{INTRODUCTION}

How much a material resists the flow of electricity is called the resistivity of the material, [1]. Electrically, soil resistivity is the extent to which a particular soil can withstand the flow of electricity through it. The resistance of an earth electrode is significantly influenced by the resistivity of the soil in which it is buried. It is therefore necessary to carry out soil resistivity measurements of a place since it is an important parameter when designing earthing. The soil is seen as a general mass that is capable of taking huge amount of charges, hence the soil is usually referred to as the earth. The soil is a core layer of the planet earth, the safest region to discharge excess charges. It is

Published on March 14, 2020.

Authors are with the Federal University of Technology, Akure, Nigeria.

(Corresponding email: mooyeleye@futa.edu.ng) important to note that the soil is not a great conductor of electricity but used as zero volt [2]

The soil is made up of different layers and offer an amount of opposition to the free flow of electricity, depends on layer. Each layer's resistivity needs to be evaluated. The unit of resistance is the Ohm $(\Omega)$ and the symbol is 'R'. Electrical resistance is not a physical material property but electrical resistivity, $\rho$, is a physical material property and measured in Ohm-meter. However, the wire's resistance would change based on the length and gauge of the wire.

According to [3] resistance is the ratio of the applied voltage to the resulting current flow denoted by (1).

$$
R=\frac{V}{I}
$$

Where: $\mathrm{V}$ is the potential difference across the conductor (Volts) and I is the current flowing through the conductor in (Amperes).

Mathematically, resistance of a conductor of a material is also defined as in (2).

$$
R=\frac{\rho \times L}{A}
$$

Where $\mathrm{L}$ is Length of the conductor $(\mathrm{m})$ and $\mathrm{A}$ is Cross sectional Area $\left(\mathrm{m}^{2}\right)$

A material with a low resistivity is a good conductor and one with a high resistivity is a bad conductor. The commonly used symbol for resistivity is $\rho$ and its unit is $\Omega$ $\mathrm{m}$. Resistivity is a degree of how much a material conducts electricity [4].

The surfer software used in this work expressed resistivity as in (3).

$$
\rho=\frac{4 \pi A R}{1+\frac{2 A}{\sqrt{\left(A^{2}+4 B^{2}\right)}-\frac{2 A}{\sqrt{\left(4 A^{2}+4 B^{2}\right)}}}}
$$

where $\rho$ is the apparent resistivity in ohm-meter $(\Omega-\mathrm{m})$, A is the distance between electrodes

which is $3 \mathrm{~m}$ in the case of this test, B is the electrode depth and $\mathrm{R}$ is the resistance value obtained on the instrument.

\section{A. Soil Resistivity Evaluation}

Soil resistivity evaluation is the process of measuring a volume of soil to determine the conductivity of the soil [4]. Conductivity is the reciprocal of resistivity, knowing conductivity of the soil, knowing the resistivity of the soil. 
The purpose of resistivity testing is to obtain a set of measurements which may be interpreted to yield an equivalent model for the electrical performance of the earthing system [1].

Soil resistivity is a necessity to designing earthing system-a system which provides safe connection between an electrical circuit and the ground for the dissipation of electrical faults,

grounding lightning strikes and maintaining the correct operation of electrical equipment [4].

One of the key factors in any electrical protection scheme is earthing. If any acceptable measures of safety are to be attained, effective and efficient earthing design and application must be made ensuring the safety of personnel and public in the vicinity of the installation $[5,6]$.

Soil resistivity evaluation is done so as to enhance earthing system (Oyubu, 2015). In an electrical installation, an earthing system connects specific parts of installation with the Earth's conductive surface. Soil resistivity is the key factor that determines what the resistance of the charging electrode will be and to what depth it must be driven to obtain low ground resistance. The resistivity of the soil varies widely throughout the world and changes seasonally. Soil resistivity is determined largely by the content of its electrolyte which consists of moisture, minerals, and the dissolved salt [7].

The lower the resistivity, the fewer the electrodes required to achieve the desired earth resistance value. It is an advantage to know the resistivity value at the planning stage as it gives an indication for how much electrode is likely to be required. When selecting the test technique for soil resistivity, factors such as maximum probe depths, lengths of cables required, efficiency of the measuring technique, cost and ease of interpretation of the data need to be considered.

Soil is not an ideal conductor in resistance. This resistance is called earth resistance of an electrode and it depends on the soil resistivity, the type and size of the electrode and the depth to which it is buried, [8].

According to [9], the best method for testing soil resistivity is the Wenner Four Point method. It uses a 4-pole digital ground resistance meter, such as the Megger meters, probes, and conductors. It requires inserting four probes into the test area.

Furthermore, determination of the local soil Power of hydrogen $(\mathrm{pH})$ is also very essential in order to determine soil resistivity and earthing system design, and other purposes ranging from soil corrosivity to agricultural practice [1] $\mathrm{pH}$ indicates the acidity or the alkalinity of a particular soil. According to Oyubu, 2015, extremely high alkalinity lowers soil resistivity and increases soil corrosivity whereas mild alkalinity withstands corrosion for a longer time. Also, soils having a pH of 5 (acidic) or below can lead to extreme corrosion rates and premature pitting of metallic objects. A neutral $\mathrm{pH}$ of about 7 is most desirable to minimise the potential for damage and makes earthing rods to withstand corrosion and carry out their protective functions on buildings/installations and appliances [1]

Many buildings have been burned down to ashes as a result of fire that exude from electricity faults. In fact, many people have been a victim of electric shock, some have been electrocuted due to improper grounding of a building. Some buildings are not even grounded at all because the owners and resident alike did not see the need to do the earthing needful or probably in an attempt to cut cost, they scrap earthing of the building from the budget.

This research work assessed soil resistivity of the proposed school of environmental building (phase III), Federal University of Technology, Akure in order to provide solution to earthing problems of damage to life and property; recommends a suitable position for the earthing $\mathrm{rod} / \mathrm{mat}$ to be buried, and recommend whether or not the soil needs to be reinforced in order to improve the conductivity of the soil and reduce the strength in earthing design and associated cost prior to electrical building installations.

\section{B. Fundamentals of soil resistivity}

Soil resistivity is a basic parameter and one of the most important methods for the design of effective grounding and lightning prevention or protection systems. [10]. Soil resistivity values widely depending on the type of terrain. Some factors that affect resistivity include type of earth Stratification, moisture content, temperature, chemical composition and concentration of dissolved salt. presence of metal and concrete pipes, tanks, large slabs, cable ducts, rail tracks, metal pipes, and topography [6] Table I illustrates how resistance and resistivity vary in the soil.

TABLE I: RESISTANCE AND RESISTIVITY VALUES FOR SEVERAL TYPES OF SOIL LAYERS [11]

\begin{tabular}{|c|c|c|}
\hline $\begin{array}{l}\text { TYPE } \\
\text { SOIL }\end{array}$ & $\begin{array}{c}\text { SOIL RESISTANCE, 3-10m depth, } \\
(\Omega)\end{array}$ & $\begin{array}{c}\text { SOIL } \\
\text { RESISTIVIT } \\
\text { Y ( } \Omega-M) \\
\end{array}$ \\
\hline Swap Soil & $3-10$ & $2-50$ \\
\hline $\begin{array}{l}\text { Farming Clay } \\
\text { and Loaming } \\
\text { Soil }\end{array}$ & $10-33$ & 100 \\
\hline $\begin{array}{ll}\text { Sandy } & \text { Clay } \\
\text { Soil } & \\
\end{array}$ & $15-50$ & 150 \\
\hline $\begin{array}{ll}\text { Moist } & \text { Sandy } \\
\text { Soil } & \\
\end{array}$ & $20-66$ & 300 \\
\hline Concrete 1:5 & N/A & 400 \\
\hline Moist Gravel & $48-160$ & 500 \\
\hline Dry Sandy Soil & $100-330$ & 1000 \\
\hline Dry Gravel & $100-330$ & 1000 \\
\hline Stoney Soil & $300-1000$ & 30000 \\
\hline Rock & N/A & $10^{\wedge} 7$ \\
\hline
\end{tabular}

\section{Soil Resistivity Measurement Techniques}

Resistivity investigations of a substation site are essential for determining both the general soil composition and degree of homogeneity. Test samples and other geological investigations provide useful information on the presence of various layers and the nature of soil material, leading to the range of resistivity at the site [12]. There are typically several layers, each with a different resistivity. There are many methods to carry out soil resistivity test. These methods include Fall of Potential method, Wenner four-pin method, Schlumberger array method, three-point method, ratio method, clamp-on earth testing method and more are used to measure the impedance of earthing system.

\section{The Wenner Array Method}

The Wenner four-pin method, Fig. 1, is the most popular and commonly used technique. There are a number of 
reasons for this popularity. These reason embraces:

i. obtaining the soil resistivity data for deeper layers without driving the test pins to those layers,

ii. no heavy equipment is needed to perform the fourpin test and

iii. the results are not greatly affected by the resistance of the test pins or the holes created in driving the test pins into the soil [13].

In this method, four probes are driven into the earth along a straight line, at equal distances a apart, driven to a depth $\mathbf{b}$. The voltage between the two inner (potential) electrodes is then measured and divided by the current between the two outer (current) electrodes to give a value of resistance R.

This raw data is usually processed with 'Surfer software' in Microsoft Excel to determine the actual resistivity of the soil as a function of depth.

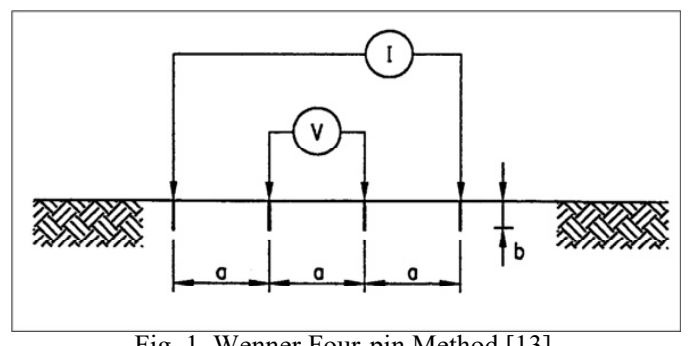

Fig. 1. Wenner Four-pin Method [13]

\section{Materials AND Methodology}

The methodology used is the ability of an earth resistance/ resistivity meter to measure the resistance and the exact point where the earthing mat/rod is to be place.

\section{A. Material Use for the Earthing Measurement}

The materials use for this project include Global Positioning System Meter (GPS), Ground Tester Meter (Model 6472-AEMC), Hammer, Measuring tape, Electrodes, cables and 12 Volts battery. Some of the materials are discussed underneath. Fig. 2 to 5 illustrate some materials used.

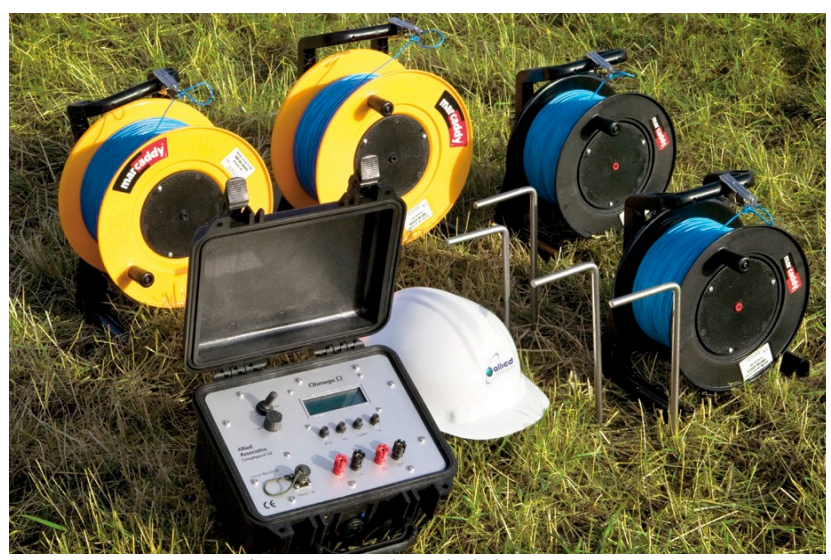

Fig. 2. Ground Resistivity Meter
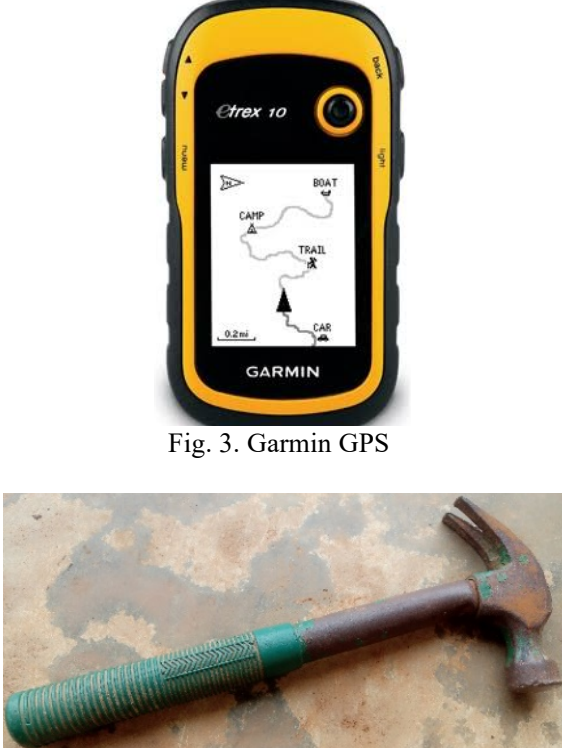

Fig. 4. Hammer

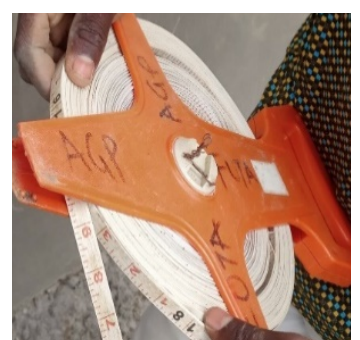

Fig. 5. Measuring Tape

\section{1) Global Positioning System (GPS)}

The GPS was used to take the coordinates of the corners of the buildings and their respective traverses. It requires $2 \mathrm{x}$ $1.5 \mathrm{Vdc}$ battery to power it. The GPS gives the value of coordinates it is placed, the UTM (Universal Traverse Mercator) value and the elevation.

\section{2) Resistivity Ground Tester Meter}

The Ground Tester Meter is a high-quality portable earth resistance meter capable of accurate measurement over a wide range of conditions is employed in this research.

\section{3) Hammer}

The hammer is used to hit and drive the electrodes into the ground. The electrodes are about $150 \mathrm{~mm}$ long which makes it impractical to drive it into the ground with bare hands in some ground hence the use of hammer.

\section{4) Measuring Tape}

The measuring tape is an instrument used to measure distances. In setting out the configuration of the test in this work, the test electrodes are placed at measured distances respectively. The measuring was used to achieve a full traverse measurement as well as the stepping. The measuring tape is about 100metres in length. The abundancy of the measuring tape made a full traverse measurement possible, easy and a lot faster.

\section{5) Test Electrodes}

The test electrodes are part of the full Ohmega resistivity meter pack and they are four in numbers. They are made of metal with a piercing pointy tip to penetrate the earth easily. For ease of measurement through a full traverse, extra eight electrodes were used to supplement the four available. 


\section{B. Soil Resistance and Resistivity Assessments}

\section{1) Soil Resistance Assessments}

A base map was generated to mark out the boundaries of the study area using a GPS after which five (5) traverses were established using Surfer software. Surfer software is a contouring and 3D mapping software program that runs under Microsoft windows. Horizontal profiling using the Wenner array configuration was carried out at an electrode spacing of $3 \mathrm{~m}$ for each of the 5 traverses. For each traverse, the test was carried out a meter away from the wall/foundation of the building for easy penetration of the electrodes to the soil, and safety requirement [14]. The measuring tape was used to take a full-length measurement and the electrodes were driven into the ground at $3 \mathrm{~m}$ intervals until the full traverse length of the building is covered. Once the electrodes have been driven into the ground at $150 \mathrm{~mm}$ depth, the terminals of the wire reel ( 2 for current electrodes and 2 for voltage electrodes) are connected to their respective crocodile clips, which in turn are used to ensure a firm grip on the electrodes. Then, the $12 \mathrm{Vdc}$ battery powers the meter. Once all the cables are the place, the ' $\mathrm{ON}$ ' button is pressed to obtain the resistance value after which a stepping size of $3 \mathrm{~m}$ is applied and the test is repeated until the full traverse length is exhausted. The corresponding values obtained are recorded for the analysis of the test.

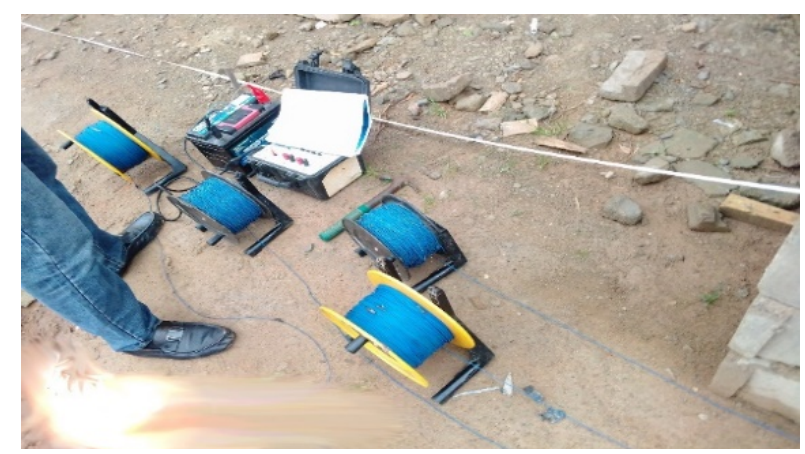

Fig. 6. Point Wenner Method Equipment Set Up

The horizontal profiling data from the Wenner configuration was plotted using Surfer software in Microsoft Excel. The plot of apparent resistance and resistivity value against distance was obtained on graphs and visually analyzed for probable targets characterized by low resistance and resistivity values.

\section{2) Soil Resistivity Determination}

The apparent resistivity formula ( $\rho$ ) for four-point method is obtained as in (3).

\section{RESUltS AND DisCUSSIONS}

\section{A. Results}

The result of the site generated from the coordinate is presented in Fig. 7.

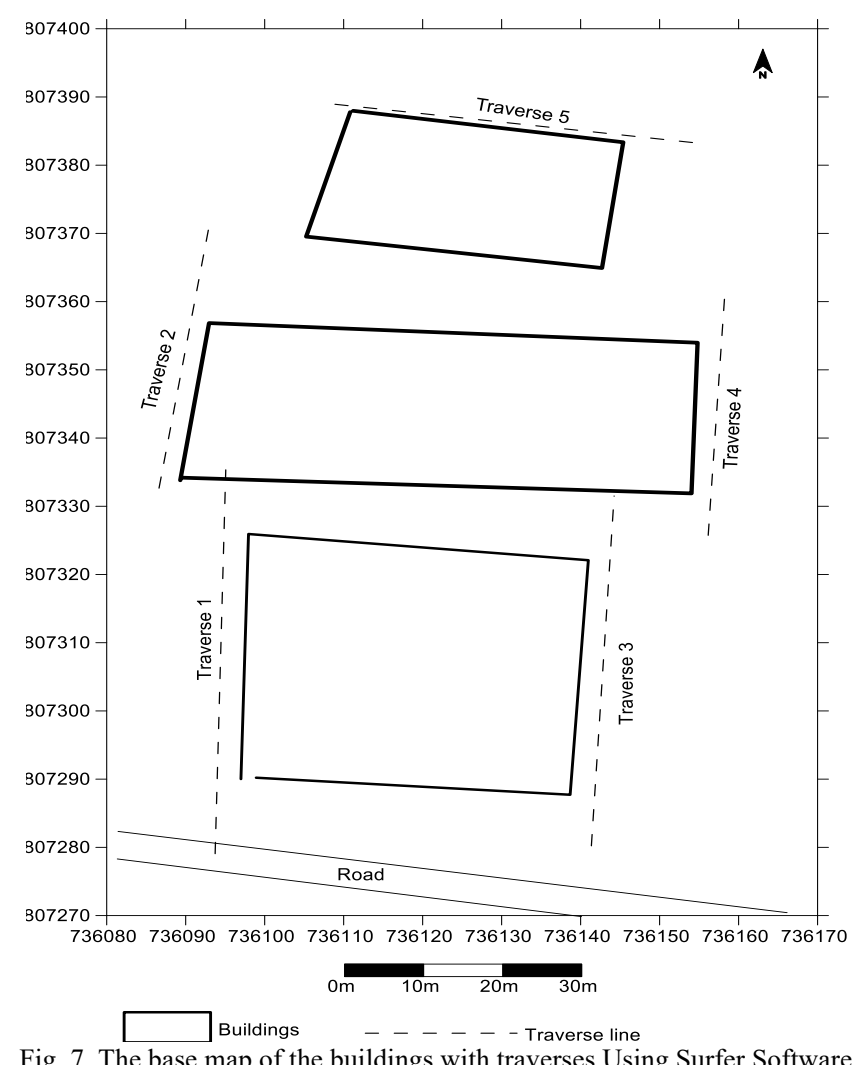

The graphical representations earth resistance values against distance is presented in Fig. 8, 10,12, 14 and 16 while Figures 9, 11,13,15 and 17 represent earth resistance values against resistivity.

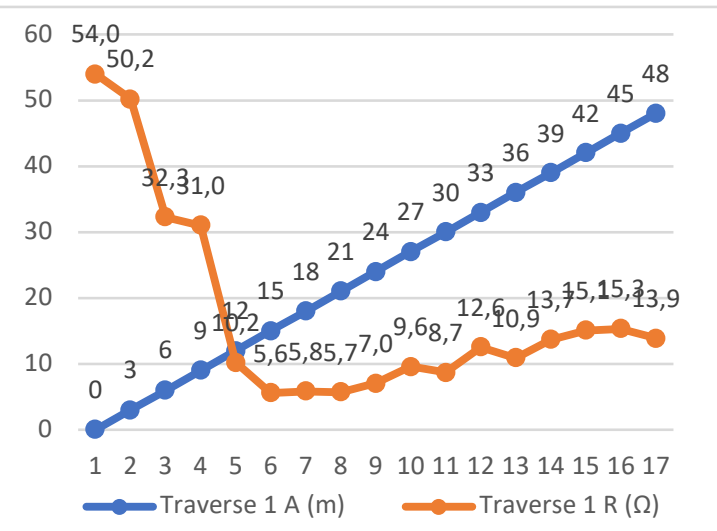

Fig. 8. Distance vs. Resistance

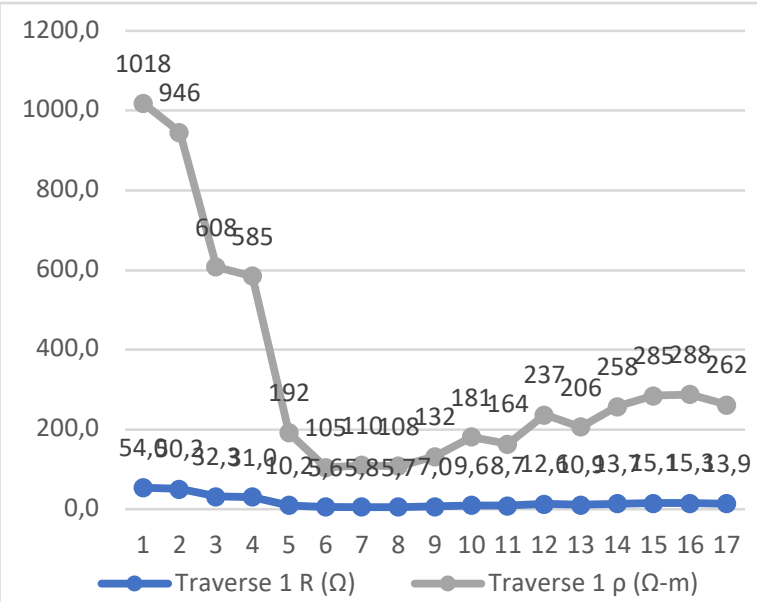

Fig. 9. Resistance Vs Resistivity 


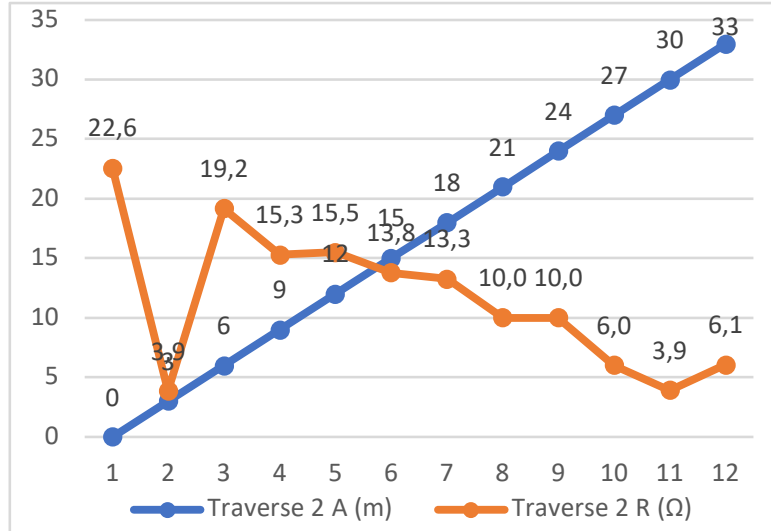

Fig. 10. Distance vs. Resistance

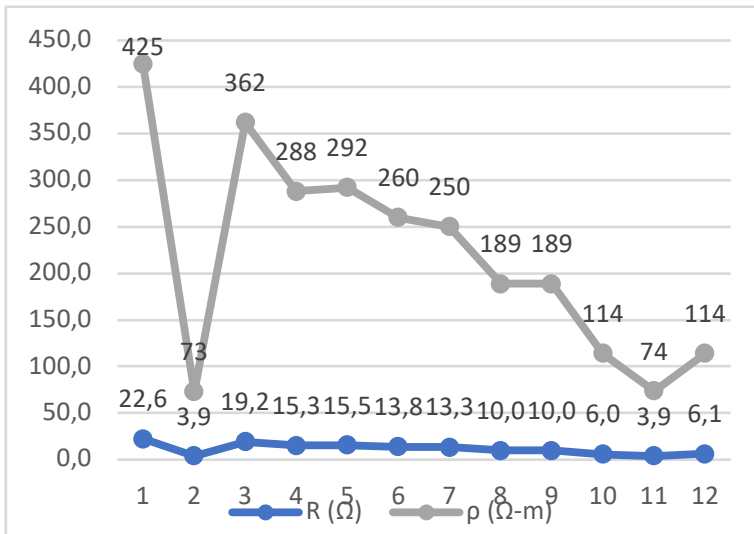

Fig. 11. Resistance vs. Resistivity

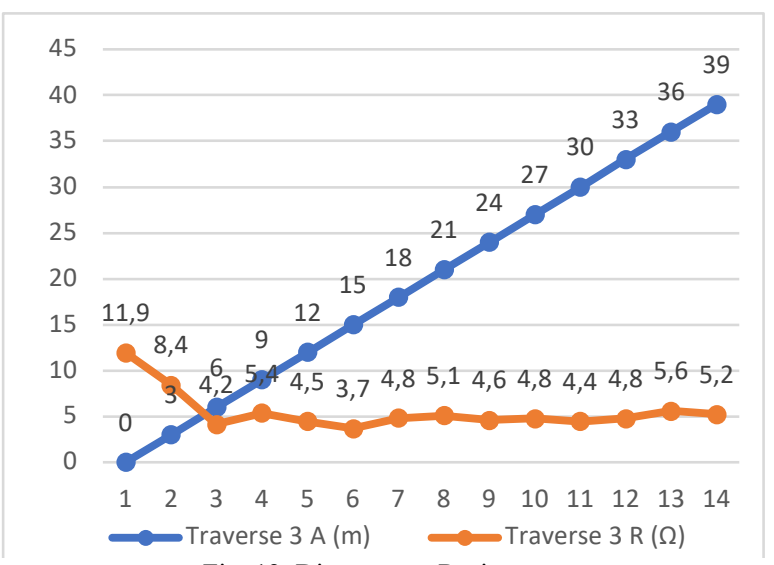

Fig. 12. Distance vs. Resistance

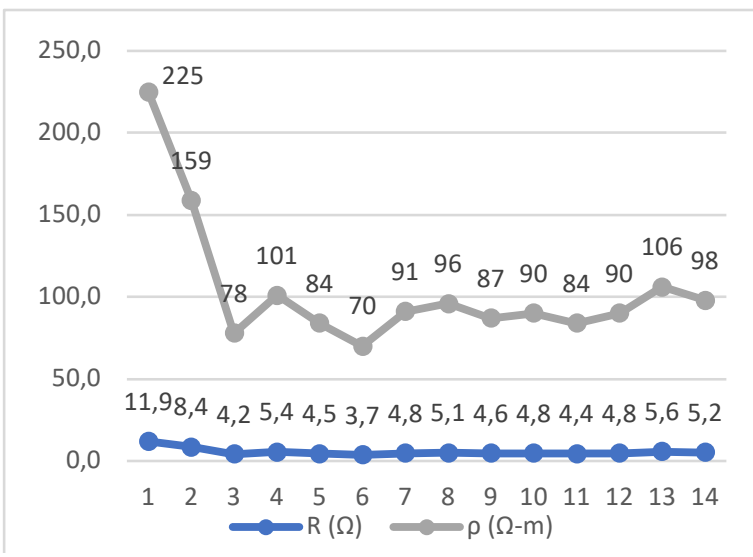

Fig. 13. Resistance vs. Resistivity

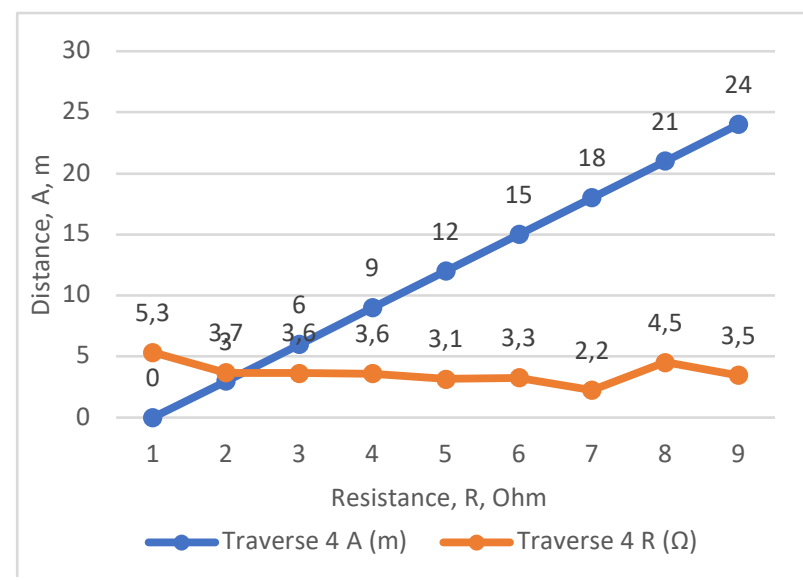

Fig. 14. Distance vs. Resistance

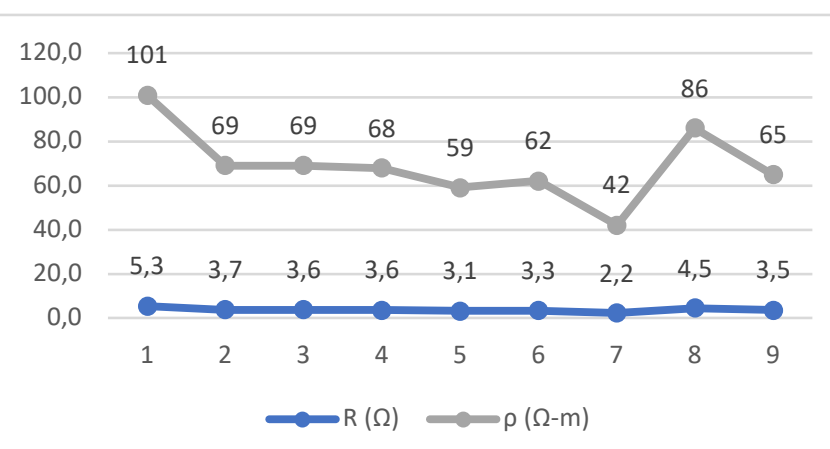

Fig. 15. Resistance vs. Resistivity

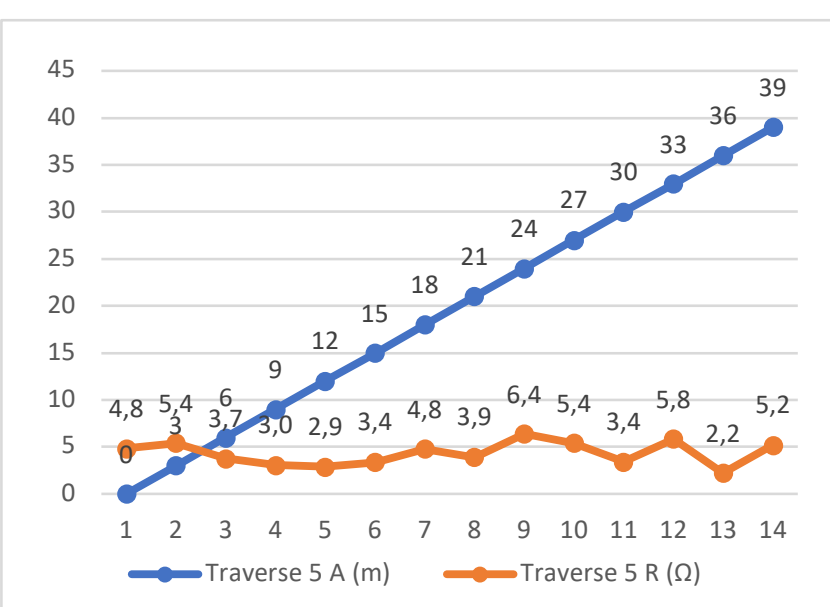

Fig. 16. Distance vs. Resistance

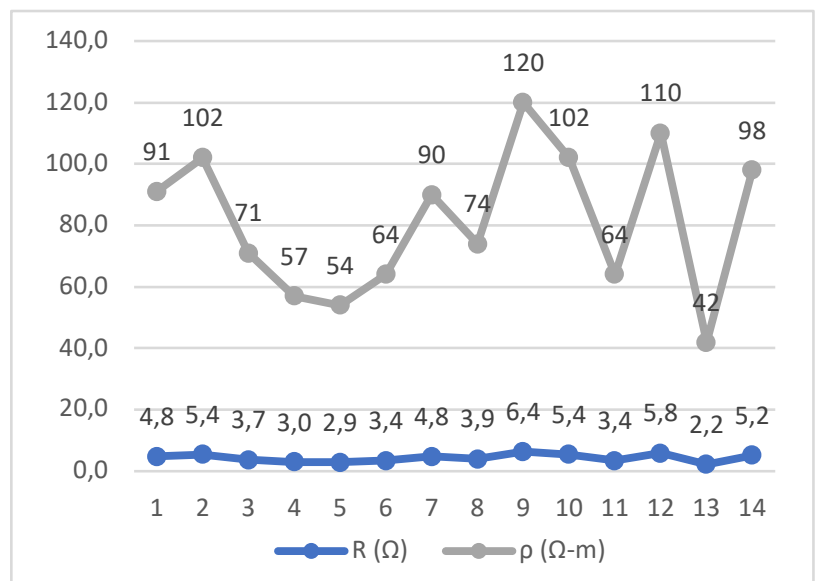

Fig.17. Resistance vs. Resistivity

\section{Discussions}

From Fig. 8 - 17, the followings deductions are obtained: 
Building 1: For the first building, two traverses were taken which are traverses 1 and 3 respectively. Each building is envisaged to have two transverses for better efficiency of the building as in Fig. 7. This is to know the point $o$ either side that has lower resistance.

Transverse 1: the earthing resistance generally varies from $5.6 \Omega$ to $54 \Omega$ and British International Standard (BIS) varies from $5.6 \Omega$ to $5.8 \Omega$. Earthing rod or mat can be installed at some points in this transverse but not at every point.

Transverse 3: the earthing resistance generally varies from $3.7 \Omega$ to $11.9 \Omega$, BIS varies from $3.7 \Omega$ to $8.4 \Omega$.; and International Electrotechnical Commission (IEC) varies from $3.8 \Omega$ to $3.9 \Omega$. Earthing rod or mat can be installed at some points in this transverse but not at every point.

Building 2: For the second building, two traverses were also taken which are traverses 2 and 4 respectively. Transverse 2: the earthing resistance generally varies from $3.9 \Omega$ to $22.6 \Omega$, BIS varies from $3.9 \Omega$ to $6.1 \Omega$, and IEC varies from $3.8 \Omega$ to $3.9 \Omega$. Earthing rod or mat can be installed at some points in this transverse but not at every point.

Transverse 4: the earthing resistance generally varies from $2.3 \Omega$ to $5.4 \Omega$, BIS varies from $2.3 \Omega$ to $5.5 \Omega$. and IEC varies from $3.8 \Omega$ to $3.9 \Omega$. Earthing rod or mat can be installed at any points in this transverse.

Building 3: For the third building, which is also the last building as at when this test was carried out, a single traverse was taken. The reason for this is due to the small distance that will mar the Wenner method to be set up in the transverse. Transverse 5 earthing resistance generally varies from $2.2 \Omega$ to $6.3 \Omega$, BIS varies from $2.2 \Omega$ to $6.3 \Omega$. IEC varies from $2.2 \Omega$ to $3.9 \Omega$. Earthing rod or mat can be installed at any points in this transverse.

Transverse 5 is the best transverse for earthing because all the points met $50 \%$ of the IEC and $100 \%$ of the BIS standard for earthing. From transverse 1 to 5 , the lest earthing value is $2.2 \Omega$ and the maximum is $54 \Omega$ which corresponds to earth resistivity of $42 \Omega \mathrm{m}$ and $1018 \Omega \mathrm{m}$ respectively.

Fig. 8, 10, 12, 14 and 16 in comparison with Fig. 9, 11, 13, 15 and 17 attests that the resistance is directly proportional to resistivity. It follows from Fig. 7 to 17, that the lower the earth resistance the lower the soil resistivity. This is sustenance to the existing literatures.

\section{CONCLUSIONS AND RECOMMENDATIONS}

\section{A. Conclusions}

i. For transverse 1, 2 and 3, earthing rod or mat can be installed at some points in this transverse but not at every point.

ii. For transverse 4 and 5 earthing rod or mat can be installed at any points in this transverse.

iii. Transverse 5 is the best transverse for earthing because all the points met BIS standard for earthing. It is closed to swamp.

iv. The lower the earth resistance the lower the soil resistivity. v. The site is okay for earthing of the three buildings without any earthing improvement at a depth of $150 \mathrm{~mm}(\mathrm{~min})$

vi. Site closest to the swamp area has less resistance value.

\section{B. Recommendations}

i. It is recommended that earthing value test should be carried out on site prior earthing installation, and

ii. Ground tester model 6472-AEMC is suitable for earthing value and soil resistivity test.

\section{ACKNOWLEDGEMENT}

I am so grateful to the Applied Geophysics Department, FUTA most especially Mr. E. A. Mamukuyomi, Mr. F. Kolawole and Mr. E.A. Adu for the preliminary data acquisition.

\section{REFERENCES}

[1] A. O. Oyubu (October, 2015). Soil resistivity and soil PH profile investigation: a case study of Delta state university faculty of engineering complex. International Journal of scientific and engineering research [Online]. 6(10). pp. 583-589. Available: http://ijser.org

[2] D. Duke (October, 2014). Earthing/Grounding system principles and methods. https://www.en.m.wikipedia.org/wiki/earthing_system. Accessed, 15 August, 2019.

[3] M. O. Oyeleye, and T. O. Ale (2019). Foundational steel reinforcement earthing evaluation case of ogomudia electrical and electronics laboratory building extension, federal university of technology Akure. Federal university of technology Akure Journal of engineering and engineering Technology. 13 pp. 96-102. Available: http://futajeet.com

[4] F. M. Omar (2012). Obtaining chemical properties through soil electrical resistivity. Journal of civil engineering research [Online]. 2(6). pp. 120-128. Available: http://article.sapub.org/10.5923.j.jce.20120206.08.html

[5] A. Kumar and Prasanna (2015). Grounding System Design for a Small hydropower station. International journal of emerging engineering research and technology [Online] (3)4. pp. 22-29. Available: http://arepub.com

[6] I. O. Akwukwaegbu and G. I. Okwe (April, 2017). soil resistivity measurement and evaluation for power system earthing a case study of radio Nigeria pacesetter F.M Umuahia Nigeria. US Open Science \& Technology journal [online]. 1(1) pp. 1-9. Available: http://arepub.com/Journals.php

[7] P. Dwarka and H. C. Sharma (October, 2015). Soil resistivity and earthing system. International journal of scientific \& engineering research [Online] 2 (9). pp. 369-380. Available: http://ijmra.us

[8] A. Gabriel, Adegboyega and O Kehinde (2011). Assessment of Soil Resistivity on Grounding of Electrical Systems: A Case Study of north-east zone, Nigeria. Journal of Academic and Applied Studies [Online]. 1(3). pp. 28-38. Available: http://arepub.com

[9] Geophysics Exploration Geophysics II Introduction to resistivity. $\begin{array}{llll}\text { Spring (2003). } & \text { pp. } & 1-4\end{array}$ http://ees.nmt.edu/outside/courses/Geop446/Docs/lab3_intro.pdfA Accessed, 20 August, 2019

[10] W.M. Telford, L.P. Geldart and R. E. Sheri. Applied Geophysics $2^{\text {nd }}$ ed. Cambridge university press, New York, 1990 Ch 5. Pp 283-292.

[11] M. O. Oyeleye and T.D Makanju (2019). Evaluation of steel reinforcement earthing in Swamp building. International journal of science and engineering investigations. 8(90). 2019, pp. 67-73. Available: http://ijsei.co/papers/ijsei-89019-11.pdf

[12] Neutral earthing in medium voltage industrial power system. SANS Standards. SABS 0200-1985,

[13] Guide for safety in AC substation earthing, IEEE Standards. 80-2000, pp 1-192.

[14] M.O. Oyeleye. Evaluation and planning of lightning protection efficacy on Nigerian high voltage installations. Ikorodu $11 \mathrm{kV}-132$ $\mathrm{kV}$ system as case study. Ph.D thesis Federal university of Technology Akure, Nigeria 2017, pp.122-125 pg. 192. 